\title{
Understanding Technology Fit Among People with HIV Based on Intersections of Race, Sex, and Sexual Behavior: An Equitable Approach to Analyzing Differences Across Multiple Social Identities
}

\author{
Elizabeth Lockhart ${ }^{1} \cdot$ DeAnne Turner ${ }^{2} \cdot$ Joseph Ficek $^{1} \cdot$ Taylor Livingston $^{3} \cdot$ Rachel G. Logan $^{4} \cdot$ \\ Stephanie L. Marhefka ${ }^{1}$ (1)
}

Accepted: 8 March 2021 / Published online: 22 March 2021

(c) The Author(s), under exclusive licence to Springer Science+Business Media, LLC, part of Springer Nature 2021

\begin{abstract}
HIV disproportionately impacts individuals based on intersecting categories (e.g. gender, race/ethnicity, behavior), with groups most at-risk deemed priority populations. Using weighted effects coding to account for differential group sizes, this study used multilevel mixed logistic models to investigate differences in eHealth use and willingness to use eHealth for HIVrelated information among priority populations. Compared to the sample average, Black men who had sex with women were less likely to use all technologies except cellphones with text-messaging and less likely to be willing to use computers and tablets. White and Hispanic men who had sex with men were more likely to use all technologies. No significant differences existed for use or willingness to use cellphones with text-messaging. Future research should consider approaches used here to account for equity and multiple intersecting social identities; practitioners may use these findings or similar local data to ensure fit between eHealth programs and priority populations.
\end{abstract}

Keywords Intersectionality $\cdot$ Technology $\cdot$ Disparities $\cdot$ HIV $\cdot$ eHealth

\section{Introduction}

Although HIV rates have declined in the United States over the past several decades, some populations are still disproportionately affected [1]. In 2019, the U.S. Department of Health and Human Services (HHS) announced "Ending the HIV Epidemic (EHE): A Plan for America"-a concentrated effort to significantly reduce HIV incidence and prevalence in the United States by 2030 [2]. The EHE plan focuses on prevention efforts within specific geographical

Stephanie L. Marhefka

smarhefk@usf.edu

1 College of Public Health, University of South Florida, 13201

Bruce B. Downs Blvd., Tampa, FL 33612, USA

2 Yale AIDS Prevention Training Program (Y-APT), Center for Interdisciplinary Research On AIDS (CIRA), Yale University, 135 College St. Suite 200, New Haven, CT 06510, USA

3 University of Nebraska-Lincoln, 816 Oldfather Hall, Lincoln, NE 68588-0368, USA

4 The Equity Experience, LLC, Tampa, FL 33607, USA areas and particular populations at increased risk of acquiring HIV, including: African Americans, Latinos, and gay, bisexual, and other men who have sex with men (MSM) of all races and ethnicities. The CDC further delineates priority populations as Black MSM, White MSM, Hispanic MSM, Black heterosexual Women (WSM), Black heterosexual Men (MSW), Hispanic heterosexual Women, and White heterosexual Women [1]. Throughout this paper we will refer to individuals who identified as Hispanic or Latino as Hispanic and the CDC defined groups will be referred to as priority populations.

Priority populations are so designated because they experience higher incidence and prevalence of HIV as well as poorer HIV-related health outcomes compared to the general population. For example, in 2018, 69\% of all new HIV infections were among MSM in the United States. Disparities are exacerbated even further when accounting for race. White MSM accounted for approximately $24 \%$ of all new HIV infections and have a $9 \%$ lifetime probability of acquiring HIV. Black MSM, however, made up $25 \%$ of all new HIV infections and have a $41 \%$ lifetime probability of acquiring HIV; Hispanic MSM made up 20\% of all new HIV infections and have a $22 \%$ lifetime probability of acquiring HIV [3, 
4]. Also, research has found that Black and Brown priority populations are less likely than their white counterparts to be virally suppressed - affecting both ongoing transmission and HIV-related health outcomes [5-7].

Over the past decade, eHealth has emerged as an effective approach of HIV prevention and care programming. A recent systematic review found that, between 2014 and 2018, 84 unique interventions used eHealth approaches for HIV care and prevention [8]. Furthermore, an additional 62 eHealth interventions were in development [8]. Technologybased interventions have been developed for most aspects of HIV prevention and care, including testing [9], antiretroviral adherence [10, 11], disclosure [12], PrEP provision [13, 14]. They have also been employed to deliver population-specific interventions to address other health behaviors disproportionately affecting people with HIV (PWH), including smoking cessation [15].

Knowledge about the devices people use and would be willing to use to access sensitive HIV-related information is critical for program development, as security, access, and comfort may vary between digital technologies. Tailored technology-based interventions have been developed for specific priority populations and delivery methods; for example, computers have been employed for Black MSM [16] and Latinos [17]; text-messaging interventions have been designed specifically for Black and Latino MSM [18-20]; tailored apps have been developed for MSM [21]; and a videoconferencing program has been developed for Black women [22].

To ensure we can maximize reach and retention in programs for $\mathrm{PWH}$, it is important to understand which technologies priority populations of PWH have and are willing to use to engage in programming for their HIV-related care. Previous research has shown the relationship, for example, between prior use of text messaging and participating in text-messaging based health interventions [23]. Willingness to use a specific digital technology may also vary due to individual circumstances and comfort levels. For example, consider an individual who shares a mobile phone with family members who do not know that individual has HIV; that individual may not be willing to receive HIV-specific text messages because their family members could intercept the messages and deduce the individuals' HIV-positive serostatus. For an individual who does not share a phone with family members, perceived ease of use and perceived security of a text-messaging app may facilitate willingness to enroll in a text-messaging program designed for PWH. Provision of technology-based programming has increased. Studies have investigated device use and willingness to use specific technologies for HIV-related programming among PWH broadly [24-30], however we have not found literature that specifically examined device use and willingness among priority populations.
One approach to understand technology-use among priority populations is to study a specific priority population independently. There is a growing body of literature that focuses exclusively on Black or Hispanic PWH [31, 32], with some exploring priority populations (e.g. Black MSM, Hispanic MSM) [33, 34] — which is important work. However, research that focuses on one specific priority population makes it difficult to compare the needs and experiences of multiple priority populations in a scientifically rigorous way.

Other research has used quantitative intersectional analyses to determine ways to compare between groups of people with multiple identities, as this may offer insights into the over-arching interacting structural factors that contribute to privilege and oppression [35-37]. The results from intersectional analyses can inform policies and interventions that aim to reduce inequities [38] as well. A range of methodologies have been used and proposed to quantitatively measure intersectionality, including conventional fixed effects regression models, where interaction terms correspond to the added effects of multiple layers of identities [39]; and multilevel models, notably the multilevel analysis of individual heterogeneity and discriminatory accuracy (MAIHDA) models $[40,41]$, which quantifies the variance among intersectional social strata by modeling them as random effects. Each of these methods have been critiqued for various reasons [42]. In particular, Evans et al. [41] critiqued the conventional fixed effects regression approach, stating that comparisons are made to a single reference category, which may reinforce notions of a default, or standard, identity - a framing that the MAIHDA methodology avoids. Such comparisons may inherently reinforce culturally-laden value judgements, such as the idea that Whites (or other privileged groups) are the norm to whom others should be compared. In 2018, 25\% of all PWH in the United States were White [43]. Why are Whites often used as the referent group in population-based PWH research if they only make up a quarter of all PWH in the United States?

A primary benefit of having a dominant comparison group, often utilized in the conventional fixed regression approach is identifying the inequities that non-majority group members experience [44]. Highlighting those inequities between groups may provide key data to drive funding and programmatic decisions for those in need. A new approach that may complement conventional fixed effects is to compare study outcomes to the sample average, instead of one group to another or one group to the dominant group.

Comparing priority populations to the sample average"the average" $\mathrm{PWH}$ - provides a unique perspective on the relative needs and experiences of those priority populations; this can help organizations estimate the specific priority populations, relative to the broader population of $\mathrm{PWH}$, more or less likely to adopt or benefit from various interventions. 
This "average" comparison may reduce culturally-laden value judgements associated with the referent group; however, it has not been widely utilized. This paper aims to address that methodological gap by using a conventional model with weighted effect coding which compares results to the sample average.

This paper has two overarching goals: 1 . to describe priority-population specific digital technology use and willingness to use various technologies for HIV-related purposes; and 2. to address a methodological gap within the extant literature on this topic by comparing priority populations to the overall sample average (instead of assuming White as the normative group).

\section{Methods}

\section{Study Design}

Data were derived from a statewide assessment of technology use among PWH in Florida [30], referred to as Project TECH. Project TECH was a multi-mode, multi-method investigation consisting of three phases. This paper reports on Phase 1, which included a brief quantitative assessment of technology use for PWH throughout Florida $(N=1268)$.

\section{Setting}

Florida is in the southern United States and has high rates of HIV incidence (3rd highest rates in the nation [45]) and prevalence (4th highest in the nation [46]). Seven of the 48 counties in the HHS plan to "End the HIV Epidemic" are located in Florida [47], making the state's number of high burdened counties second to only California. An estimated 119,661 people with HIV are living in Florida [45], 75\% $(89,925)$ of whom are in care, and approximately 56,220 of whom are receiving services from the Ryan White program [48]. Demographically, state rates of HIV are higher among men (71.9\% vs. $28.1 \%$ female) and Black men and women (45.9\%, compared to $23.3 \%$ Latino and $28.0 \%$ White) [49].

\section{Study Participants and Data Collection}

Data were collected from June 2016-April 2017 via a partnership between Ryan White Case Managers (RWCM; case managers employed under the Ryan White HIV/AIDS Program who serve PWH) and researchers [50]. RWCMs: (a) asked clients with whom they naturally came into contact if they would like to participate; (b) completed informed consent; and (c) read the 10 questions [50] aloud to the participant. Most RWCMs entered participant responses into a secure online system via Qualtrics; some completed the assessments on paper and mailed them to the study team, who entered data into Qualtrics. Participants had the option to be entered into a raffle to receive one of $500 \$ 15$ gift cards.

\section{Measures}

See Table 1 for information on measures used. Participants were placed into priority populations based upon their selfidentified gender, race, and sexual behavior and transmission risk [51, 52], resulting in eight priority population groups $(N=1120)$ as identified by the CDC: Black MSM, Hispanic MSM, White MSM, Black WSM, Hispanic WSM, White WSM, Black MSW, and Hispanic MSW. Those who identified as both Hispanic and another race were identified as Hispanic $(n=84)$. To delineate the greatest possible potential for HIV exposure, if a male participant identified as having ever had sex with a man he was classified as MSM, even if he also reported ever having had sex with a woman.

\section{Statistical Analysis}

Use of and willingness to ever use each digital technology for HIV-related purposes were examined (yes/no) for: (1) a desktop, laptop, or notebook computer (henceforth computer); (2) a tablet computer; (3) a mobile phone with text messaging; (4) apps on a mobile phone; and (5) internet on a mobile phone.

For each outcome, a mixed logistic model was fit with age group (18 to 29,30 to 49,50 to $64,65+$ ), geography (rural, suburban, urban) [30], and priority population grouping as fixed factors. Models for willingness to use a device also included persons with and without prior use. Prior use of that same device (yes/no) was added to the model as an additional factor. For all models, the AIDS Service Organization through which an individual took the survey was included as a random intercept - this served as a proxy for geographic effects at the county level. Observations with missing values were excluded from model fitting via case-wise deletion.

To avoid comparing effects to a designated "reference" group, weighted effect coding was used [53], so that each $\beta$ coefficient represents the difference from the grand mean of all groups (weighted by sample size) on the log odds scale. Adjusted odds ratios and $95 \%$ confidence intervals were computed for each effect. Odds ratios were considered significantly different from 1.0 using a two-tailed t-test at the $\alpha=0.05$ level. For each outcome, the model estimate of the mean prevalence was computed for the weighted sample average, along with the intracluster correlation coefficient. Descriptive statistics (sample size and prevalence of each outcome, stratified by model covariates) were also 
Table 1 Measures

\begin{tabular}{|c|c|c|}
\hline Construct & Question & Specifications \\
\hline Age & How old are you in years? & $\begin{array}{l}\text { Categorized into four age groups: } 18 \text { to } 29 ; 30 \text { to } 49 ; 50 \text { to } \\
64 ; 65+[57]\end{array}$ \\
\hline Geography & What is your ZIP code? & $\begin{array}{l}\text { Participants categorized as living in a rural, suburban, or } \\
\text { urban setting based on USDA } 2010 \text { RUCA classifica- } \\
\text { tions. A detailed explanation of this process has been } \\
\text { outlined in greater detail elsewhere [blinded for review] }\end{array}$ \\
\hline Race/ethnicity $^{\text {a }}$ & $\begin{array}{l}\text { The next question is about your race and ethnicity. Tell } \\
\text { me yes or no for each one. Are you: Hispanic or Latino; } \\
\text { Black of African American; White or Caucasian; Asian } \\
\text { or Other Pacific Islander; Native American }\end{array}$ & $\begin{array}{l}\text { Participants responded "yes" or "no" for each race/ethnic- } \\
\text { ity }\end{array}$ \\
\hline Sexual behavior & $\begin{array}{l}\text { Have you ever had sex with a man? Have you ever had } \\
\text { sex with a woman? }\end{array}$ & Participants responded "yes" or "no" for each question \\
\hline Gender $^{\mathrm{b}}$ & $\begin{array}{l}\text { What is your gender? Are you female? Male? Trans } \\
\text { male? Trans female? Another gender? }\end{array}$ & Participants responded "yes" or "no" for each question \\
\hline Technology use & $\begin{array}{l}\text { Do you use: a desktop, laptop, netbook, or notebook } \\
\text { computer; a tablet computer like an iPad, Samsung Gal- } \\
\text { axy, or Windows tablet; a mobile phone or cellphone } \\
\text { with text messaging; apps on your mobile phone or } \\
\text { cellphone; and the internet on your mobile phone or } \\
\text { cellphone }\end{array}$ & $\begin{array}{l}\text { Participants responded "yes" or "no" for each digital } \\
\text { technology }\end{array}$ \\
\hline Technology willingness ${ }^{\mathrm{c}}$ & $\begin{array}{l}\text { Earlier I asked you about the devices you have used in } \\
\text { the past, now I will ask you about devices you would } \\
\text { ever be willing to use. Would you EVER be willing to } \\
\text { use the following devices to access information about } \\
\text { HIV? }\end{array}$ & $\begin{array}{l}\text { Participants responded "yes" or "no" for each digital } \\
\text { technology }\end{array}$ \\
\hline
\end{tabular}

${ }^{a}$ Due to sample size restrictions and efforts to ensure anonymity, only participants who identified as Black, White, or Hispanic/Latinx were used in further analyses

${ }^{b}$ Due to sample size restrictions and efforts to ensure anonymity, only participants who identified as male or female were used in further analyses

${ }^{\mathrm{c}}$ All participants were asked these questions regardless of their prior use of the devices

computed. All analyses were done in SAS 9.4. The mixed logistic model was fit using PROC GLIMMIX.

\section{Results}

\section{Use of Device}

A total of 1120 participants completed the survey. Participant were, on average, $48.5( \pm 11.8)$ years, Black $(55 \%)$, male $(60 \%)$, and indicated they had sex with men $(78 \%)$. The percentage of use of each digital technology is provided in Table 2. Adjusted odds ratios and $95 \%$ confidence intervals (CI) for each priority population grouping are presented in Table 3. All results are compared to the sample average. The odds of using a desktop, laptop, or notebook computer by Hispanic MSM and White MSM were 2.7 (95\% CI: $1.8,4.0)$ and $3.1(2.1,4.7)$ times greater than the average, respectively. Conversely, the odds of using these technologies were 0.7 times lower than the sample average for Black WSM (0.6, 0.9), 0.6 times lower for Hispanic WSM (0.4, $1.0)$, and 0.4 times lower for Black MSW $(0.3,0.6)$. For all other priority population groupings, the odds of using these technologies were not significantly different from average. Hispanic MSM and White MSM were $1.7(1.2,2.4)$ and $1.8(1.3,2.6)$ times more likely to use a tablet, while Black MSW and Hispanic MSW were $0.5(0.4,0.7)$ and $0.5(0.3$, $0.9)$ less likely to use a tablet. Odds of using a mobile phone with text messaging were not significantly different for any priority population groupings. The odds of using apps on a mobile phone by Hispanic MSM and White MSM were 1.9 $(1.2,3.0)$ and $1.9(1.2,2.8)$ greater than the sample average, respectively. Odds of app use were $0.6(0.4,1.0)$ times lower for Hispanic WSM and $0.6(0.4,0.8)$ times lower for Black MSW. Hispanic MSM had $2.3(1.4,3.7)$ and White MSM had $1.6(1.1,2.5)$ times greater odds for using the internet on a mobile phone. Black WSM had $0.7(0.6,0.9)$ times lower odds and Black MSW had $0.5(0.3,0.6)$ times lower odds of using the internet on a mobile phone.

\section{Willingness to Use Device}

The unadjusted prevalence of willingness to use each digital technology is provided in Table 2. Adjusted odds ratios and $95 \%$ confidence intervals are provided in Table 4 . All results are compared to the sample average. White MSM 


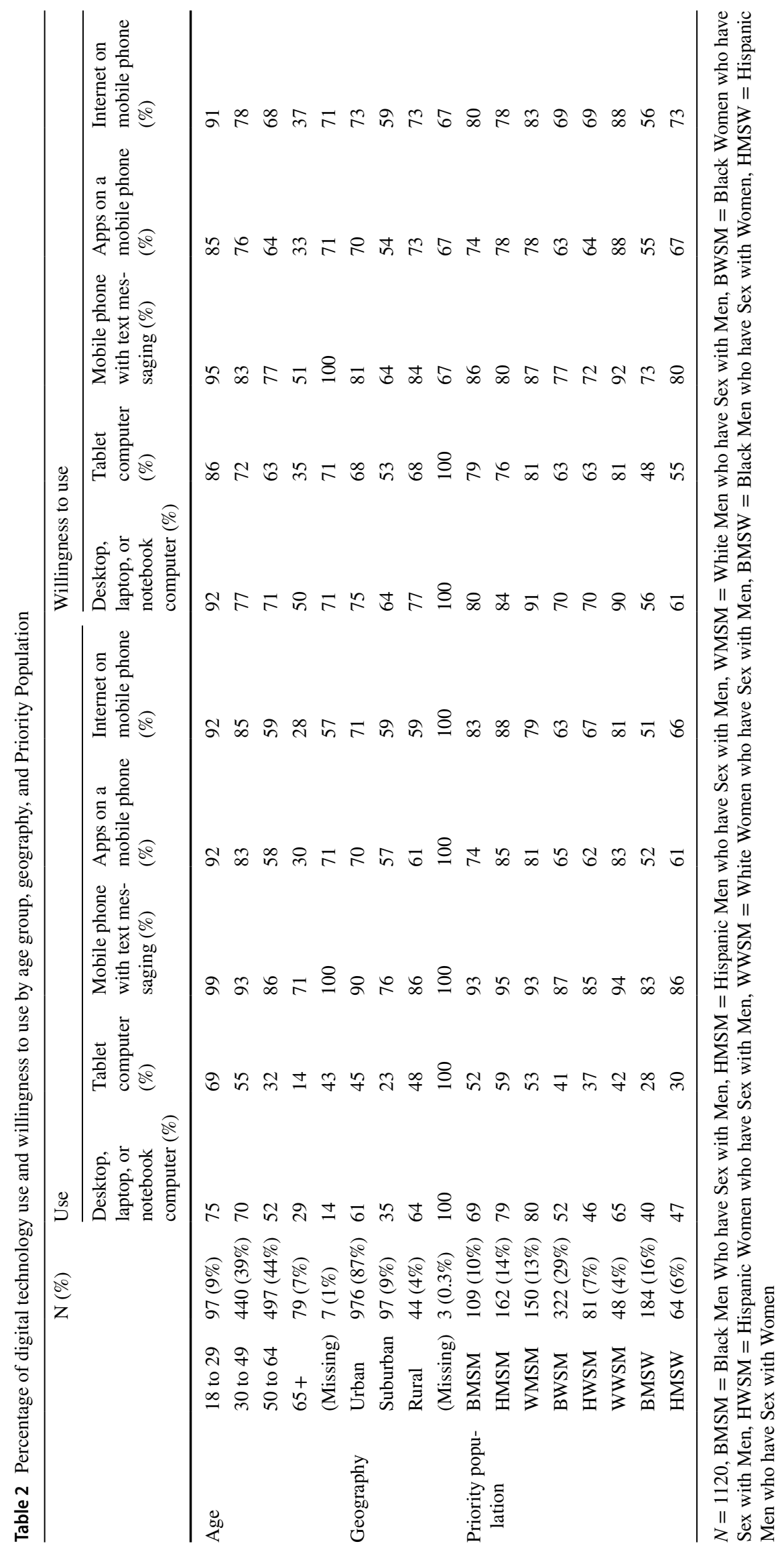




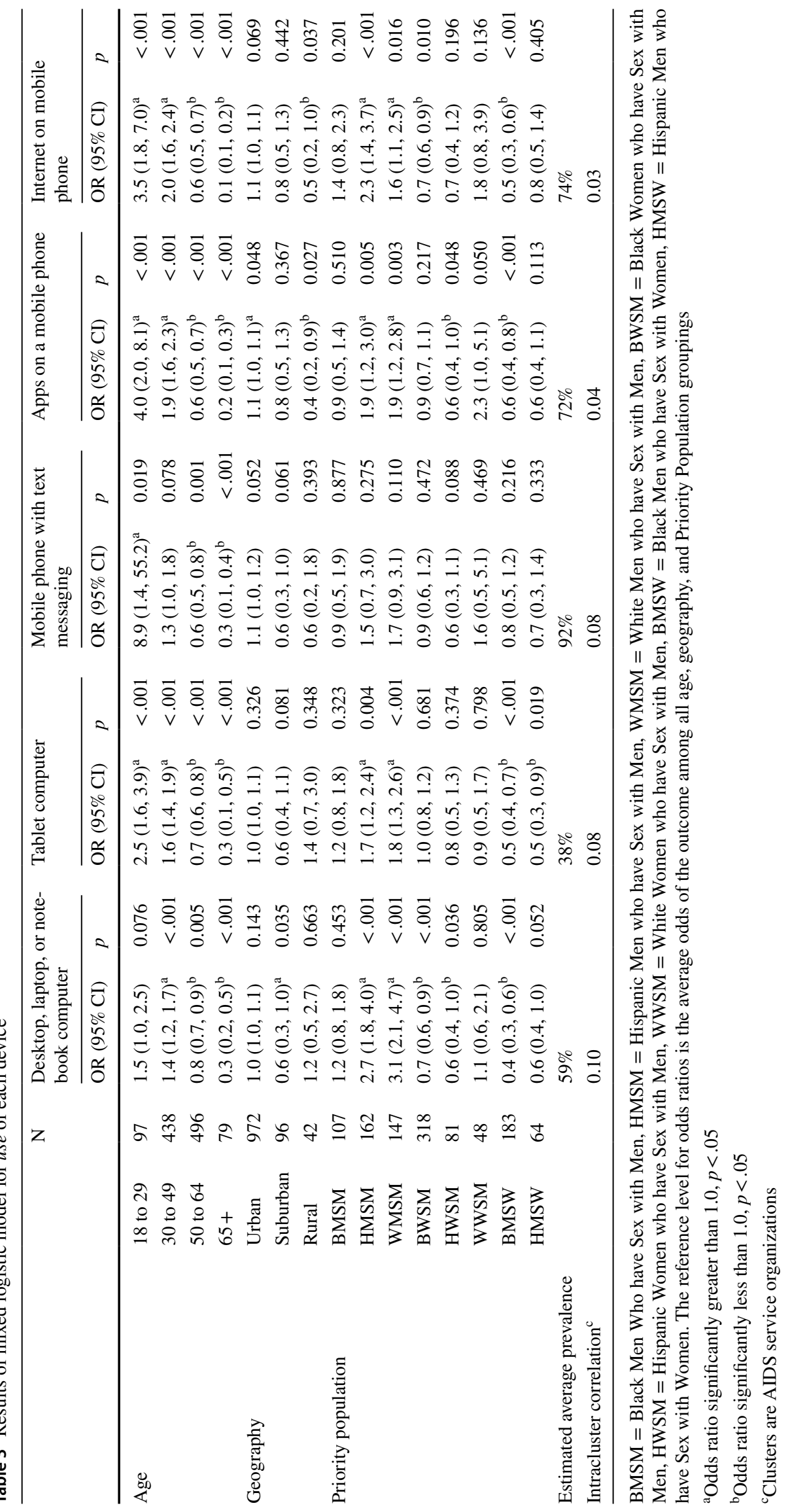




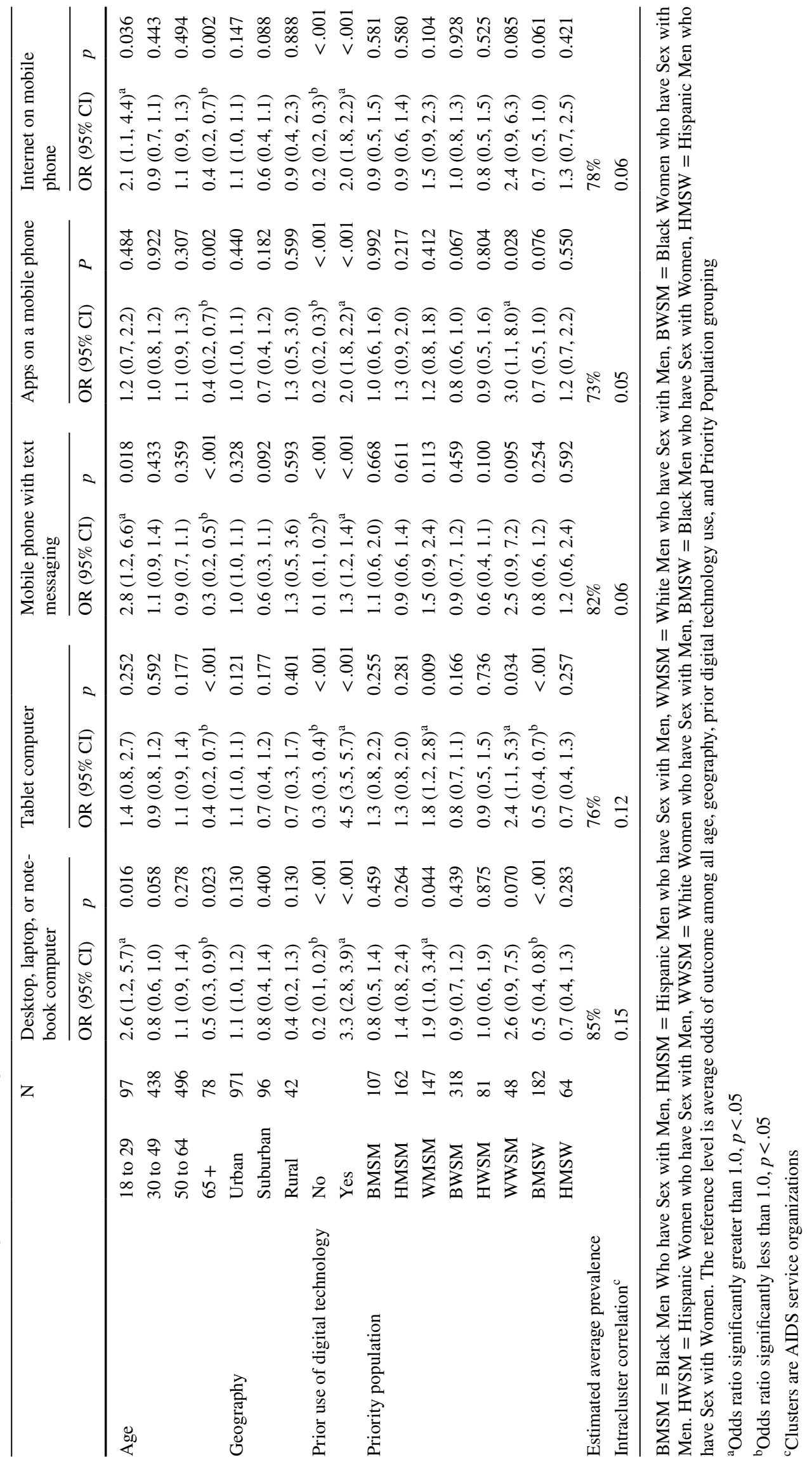


were 1.9 times $(95 \%$ CI: $1.0,3.4)$ more likely to be being willing to use a computer, while Black MSW 0.5 times (0.4, 0.8 ) odds among were significantly lower. White MSM and White WSM had 1.8 times $(1.2,2.8)$ and 2.4 times $(1.1,5.3)$ greater odds, respectively of being willing to use a tablet computer, while Black MSW had 0.5 times $(0.4,0.7)$ lower odds. The odds of willingness to use a mobile phone with text messaging and using internet on a mobile phone were not significantly different for any of the priority population groupings. White WSM were 3.0 times $(1.1,8.0)$ more likely to be willing to use apps on a mobile phone.

\section{Discussion}

Our study sought to understand differences in use and willingness to use specific digital technologies for HIV-related purposes between priority population groups. Findings indicate that digital technology use and willingness to use digital technologies for HIV-related purposes varied based on priority population. Overall, compared to the sample average, White and Hispanic MSM were more likely to use all digital technologies except for cellphones with text messaging, while Black MSW were less likely to use all digital technologies except for cellphones with text messaging. White MSM were more likely to be willing to use computers and tablets, while White WSM were more likely to be willing to use tablets and apps compared to the sample average. Black MSW were less likely to be willing to use computers and tablets compared to the sample average. This study supports the idea that the cellphone is the great equalizer [54], as people have greater access to cellphones compared with other digital technologies. However, it appears that cellphones are only the great equalizer as text messaging devices, not as devices to be used for the internet or apps. Additionally, this study adds to the literature highlighting the need for developing and providing different types of digital technology programs and interventions among $\mathrm{PWH}$, as not all technologies fit with the preferences of potential users [30]. Finally, by comparing to the sample average, this study highlights potential biases that may impact technology-based programming, as traditional comparison groups (e.g. White or men) should not dictate the technology preferences for all.

While there were no significant differences based on age, geography, or prior digital technology use, there were overall sample differences between use of digital technologies and willingness to use them for HIV-related purposes. Over half of participants used (59\%) computers, however many more were likely to be willing to use computers for HIV-related purposes $(85 \%)$. This same phenomenon was also true of tablets; only $38 \%$ of participants said they used tablets, but $76 \%$ were willing to use them for HIV-related purposes. Seplovich et. al [55] found similar levels of computer and tablet use, albeit with a smaller sample size. Some potential reasons why our sample had lower use of digital technologies but higher willingness to use those same digital technologies for HIV-related purposes may include: limited access to the technology [56], limited technology literacy [57], lack of confidence/comfort with technologies [58], and privacyrelated concerns [30,59]. Because more people are willing to ever use digital technologies for HIV-related purposes than currently use those technologies, future interventions should focus on both increasing access to technologies and creating HIV-specific content for computer and tablets. Conversely, $92 \%$ of participants reported using a mobile phone with text-messaging; fewer ( $82 \%$ ) were willing to use that same digital technology for HIV-related purposes. While research has focused on text-messaging based programs for PWH $[23,60]$ with promising results, future research should examine which priority populations are willing and unwilling to use their mobile phones for HIV-related purposes and determine the facilitators of and barriers to uptake.

This analysis was built on our previous work [23]. Due to the differences in methods used, findings differ. For example, in our original analyses in which White PWH were considered the referent group and sexual behavior categories were not considered in conjunction with race and ethnicity, Black individuals were less likely to both use and be willing to use digital technologies (excepting mobile phones with text messaging) for HIV-related purposes. Yet findings in the current analyses suggest Black $M S W$ were no less likely than the sample average to be willing to use apps or internet on a mobile phone and Black $M S M$ were no less likely to be willing to use any of the digital technologies. Also for example, in the original analyses, Hispanic individuals were less likely than White PWH to be willing to use tablets and mobile phones with text messaging. In the current analyses, Hispanic MSM, Hispanic MSW, and Hispanic WSM were no less likely than the sample average to be willing to use either tablets or mobile phones with text messaging. The utility of the analyses and their related findings may be perceived differently depending on the goals of the reader.

Although this study did not employ a theoretical framework a priori, intersectionality framework may be useful in interpreting and analyzing the data post hoc, especially to understand factors that may be unmeasurable but may impact outcomes. Intersectionality is a conceptual framework developed by Black feminist legal scholar Kimberlé Crenshaw [61] to highlight how multiple marginalized social identities (such as race and gender) interact and produce greater inequities than a single marginalized identity alone. Crenshaw's synthesis suggests that without rac-ism, discrimination, prejudice, stigma, and other structural oppressions, social identities cannot be considered the cause of inequalities. Instead, it is structural oppression that produces differential treatment in society that manifests inequalities, 
such as particular marginalized populations (e.g., Black and Hispanic men and women) being disproportionately vulnerable to HIV. Intersectionality posits that inequities or privileges are not simply the result of additive effects of multiple social identities, but rather the synergistic effects of all social identities within existing sociopolitical contexts [61, 62]. For instance, what it means to be an Hispanic man who has sex with men is different than the sum of being Hispanic, a man, and a MSM. How an Hispanic MSM is positioned in society and experiences structural oppression manifests differently than those with less stigmatized identities, such as White MSW. The "anticategorical complexity" of intersectionality articulated by McCall [63], is that society is too complex to be understood by examining any singular social identity. Rather, the social identities of race, gender, and sexuality only have significance when understood as intersecting identities of disadvantage and privilege [63, 64].

Use of an intersectional framework in HIV-related research is a developing field, and its quantitative application to understanding how multiple social identities influence uptake of HIV-related programming is under explored. Quantitatively, intersectionality has been utilized to help explain the experience of different types of stigma [65-68] and HIV testing [69]. Intersectionality framework has been used most frequently in qualitative studies with regards to HIV and has examined experiences related to stigma [70], PrEP usage [71], and access to care [72]. Our work builds upon this research and quantitatively examines how priority populations may use or be willing to use digital technologies for HIV-related programming.

Research Implications Methodologically, this study builds upon previous research that has investigated appropriate quantitative methods that account for an individual's multiple identities [41, 73]. Our analysis models' intersectional categories with fixed effects, which enables traditional inference using confidence intervals. Yet through our use of weighted effect coding, these effects measure differences from the observed sample average, rather than differences from a designated reference group. Hence, our approach allowed us to address inequities without relying on a reference, or culturally dominant, group as the norm while using a baseline that reflects the actual, relative composition of intersectional groups in our sample.

\section{Practice Implications}

For mHealth program decision-makers, findings of this and our prior study [30] suggest this: if text messaging will meet the needs of the HIV-specific priority population and will achieve the intended programmatic goals, text messaging with tailored content for each specific priority population [74], should be used to ensure the greatest reach. However, to reach the greatest percentage of the priority population when the goals of the programming cannot be achieved with text messaging (alone), agencies looking to provide programming to one priority population may want to consider descriptive statistics specific to their priority population provided here or local data on the priority population to determine the technology to which most people have access. Agencies looking to provide a program to multiple priority populations may look to this paper or analyses like these to determine which technology will meet the needs of program delivery while being likely to reach the largest number of participants across the priority populations in focus.

Despite the strengths of this study, our sample only included clients receiving services from the Ryan White Program [75] in Florida. People living in Florida and receiving Ryan White services could be different than those in other states and/or those who are not receiving Ryan White services. It is possible that participants could share digital technologies with other people, which may influence their willingness to use those devices specifically for HIV-related purposes. We did not ask, however, about whether sharing occurred. Although we examined multiple identities a person may have (e.g. race, gender, and sexual behavior), there are certainly other identities (e.g. social class) that were not included in these analyses. Additional identities, or other factors, could also impact use of technology and willingness to use technology for HIV-related programming. Due to inadequate sample size for transgender men and women, we were not able to include those priority populations in the study. Furthermore, the potential modifying effects of age and geography could not be tested, since the sparseness of the data prevented the models from converging. This was the case even if categories were grouped together to form larger cell sizes, i.e., by combining suburban and rural geographic categories, and combining 50-64 and 65+age groups. Data in this study were collected prior to the COVID-19 pandemic. Both use and willingness to use digital technologies may change over time and the increasing digitization of life in response to COVID-19-related distancing measures may accelerate related changes. Studies that track those changes may be critical for guiding programming decisions.

The strengths of this study outweigh the limitations. Our study included a large sample from Florida, a state with high HIV prevalence and incidence [45]. Our examination considered several intersecting identities-which may provide a holistic understanding of who may, or may not, be willing to take part in technology-based HIV programming. Importantly, our novel approach of using weighted effects accounts for different size groupings and addresses a critique of other intersectional quantitative approaches that assume multiple social identities are equally sized [42]. Information about priority populations can inform intervention delivery. For example, data like these can guide decisions about providing 
access to those who do not currently use digital technologies or creating specific programs for those who are willing to use their digital technologies for HIV-related purposes. Some may be concerned that relying on the sample average uses data from all groups. It is true that when comparing groups to the grand mean, their effects will appear more modest than when comparing two groups at opposing extremes. This was a deliberate choice for this analysis since the population average was deemed a more useful and consistent reference point than any single, isolated group. It is worth noting that any perceived attenuation from the use of effect coding (as opposed to standard reference coding) is not the result of statistical bias. The different coding schemes yield equivalent models with the same fit statistics and fitted values.

Future research should continue to develop quantitative methods to better understand how particular priority population groups may be likely to engage in HIV programming, with results leading to socially informed, "relevant, inclusive and effective policy solutions that enhance equality" [64]. Additionally, employing qualitative methods to further explore technology use experiences and preferences will be critical for understanding how eHealth approaches can be optimized for fit with individual priority populations-most especially groups that face intersecting structural oppressions. Our findings suggest further inquiry is needed to examine why willingness to use technologies for HIV-related purposes varies across priority populations and determine what aspects of programs could be modified to increase uptake among HIV priority populations.

Acknowledgements The authors would like to thank those who participated in this research.

Funding This work was supported by NIH Award \# 5R21MH108468, Research Towards Implementing Technology-Based Prevention with Positives.

\section{Declarations}

Conflict of Interest The authors have no relevant financial or non-financial interests to disclose.

Ethical Approval Approved by Florida Department of Health IRB \#2016-08-USF.

Consent to Participate Verbal informed consent was obtained from all participants.

\section{References}

1. Centers for Disease Control and Prevention. Populations at greatest risk 2015 [updated November 16, 2015. Available from: https://www.cdc.gov/hiv/policies/hip/risk.html.
2. U.S. Department of Health \& Human Services. Ending the HIV epidemic 2019 [Available from: https://www.hiv.gov/federalresponse/ending-the-hiv-epidemic/hiv-in-america.

3. U.S. Department of Health \& Human Services. What is the impact of HIV on racial and ethnic minorities in the U.S.? 2020 [updated May 14, 2020. Available from: https://www.hiv.gov/hiv-basics/ overview/data-and-trends/impact-on-racial-and-ethnic-minorities.

4. Hess KL, Hu X, Lansky A, Mermin J, Hall HI. Lifetime risk of a diagnosis of HIV infection in the United States. Ann Epidemiol. 2017;27(4):238-43.

5. Beer L, Bradley H, Mattson CL, Johnson CH, Hoots B, Shouse RL. Trends in racial and ethnic disparities in antiretroviral therapy prescription and viral suppression in the United States, 20092013. J Acquir Immune Defic Syndr. 2016;73(4):446-53.

6. Nwangwu-Ike N, Frazier EL, Crepaz N, Tie Y, Sutton MY. Racial and ethnic differences in viral suppression among HIV-positive women in care. J Acquir Immune Defic Syndr. 2018;79(2):e56-68.

7. Sheehan DM, Fennie KP, Mauck DE, Maddox LM, Lieb S, Trepka MJ. Retention in HIV care and viral suppression: Individual- and neighborhood-level predictors of racial/ethnic differences, Florida, 2015. AIDS Patient Care STDS. 2017;31(4):167-75.

8. Maloney KM, Bratcher A, Wilkerson R, Sullivan PS. Electronic and other new media technology interventions for HIV care and prevention: A systematic review. J Int AIDS Soc. 2020. https:// doi.org/10.1002/jia2.25439.

9. Bauermeister JA, Pingel ES, Jadwin-Cakmak L, Harper GW, Horvath $\mathrm{K}$, Weiss $\mathrm{G}$, et al. Acceptability and preliminary efficacy of a tailored online HIV/STI testing intervention for young men who have sex with men: The Get Connected! program. AIDS Behav. 2015;19(10):1860-74.

10. Shah R, Watson J, Free C. A systematic review and meta-analysis in the effectiveness of mobile phone interventions used to improve adherence to antiretroviral therapy in HIV infection. BMC Public Health. 2019;19(1):915.

11. Wang Z, Zhu Y, Cui L, Qu B. Electronic health interventions to improve adherence to antiretroviral therapy in people living with HIV: Systematic review and meta-analysis. JMIR Mhealth Uhealth. 2019;7(10):e14404.

12. Marhefka SL, Buhi ER, Baldwin J, Chen H, Johnson A, Lynn V, Glueckauf R. Effectiveness of healthy relationships video-groupA videoconferencing group intervention for women living with HIV: Preliminary findings from a randomized controlled trial. Telemed e-Health. 2014;20(2):128-34. https://doi.org/10.1089/ tmj.2013.0072.

13. Touger R, Wood BR. A review of telehealth innovations for HIV Pre-Exposure Prophylaxis (PrEP). Curr HIV/AIDS Rep. 2019;16(1):113-9.

14. Pasipanodya EC, Jain S, Sun X, Blumenthal J, Ellorin E, Corado $\mathrm{K}$, et al. Trajectories and predictors of longitudinal preexposure prophylaxis adherence among men who have sex with men. J Infect Dis. 2018;218(10):1551-9.

15. Marhefka SL, Turner D, Lockhart E, Rivara A, Wang W, Shuter J. Meeting our patients "Where They Are": Video-group smoking cessation for people living with HIV. J Assoc Nurses AIDS Care. 2018;29(2):338-344. https://doi.org/10.1016/j.jana.2017.09.007.

16. Klein CH, Kuhn T, Huxley D, Kennel J, Withers E, Lomonaco CG. Preliminary findings of a technology-delivered sexual health promotion program for Black men who have sex with men: Quasi-experimental outcome study. JMIR Public Health Surveill. 2017;3(4):e78.

17. Kurth AE, Chhun N, Cleland CM, Crespo-Fierro M, Parés-Avila JA, Lizcano JA, et al. Linguistic and cultural adaptation of a computer-based counseling program (CARE+ Spanish) to support HIV treatment adherence and risk reduction for people living with HIV/AIDS: A randomized controlled trial. J Med Internet Res. 2016;18(7):e195. 
18. Levy ME, Watson CC, Wilton L, Criss V, Kuo I, Glick SN, et al. Acceptability of a mobile smartphone application intervention to improve access to HIV prevention and care services for Black men who have sex with men in the District of Columbia. Digit Cult Educ. 2015;7(2):169-91.

19. Huang E, Marlin RW, Young SD, Medline A, Klausner JD. Using Grindr, a smartphone social-networking application, to increase HIV self-resting among Black and Latino men who have sex with men in Los Angeles, 2014. AIDS Educ Prev. 2016;28(4):341-50.

20. Senn TE, Braksmajer A, Coury-Doniger P, Urban MA, Rossi A, Carey MP. Development and preliminary pilot testing of a peer dupport text messaging intervention for HIV-infected Black men who have sex with men. J Acquir Immune Defic Syndr. 2017;74 Suppl 2(Suppl 2):S121-s7.

21. Sullivan PS, Driggers R, Stekler JD, Siegler A, Goldenberg T, McDougal SJ, et al. Usability and acceptability of a mobile comprehensive HIV prevention app for men who have sex with men: A pilot study. JMIR Mhealth Uhealth. 2017;5(3):e26.

22. Junkins A, Psaros C, Ott C, Azuero A, Lambert CC, Cropsey K, et al. Feasibility, acceptability, and preliminary impact of telemedicine-administered cognitive behavioral therapy for adherence and depression among African American women living with HIV in the rural South. J Health Psychol. 2020:1359105320926526.

23. Taylor D, Lunny C, Lolić P, Warje O, Geldman J, Wong T, et al. Effectiveness of text messaging interventions on prevention, detection, treatment, and knowledge outcomes for sexually transmitted infections (STIs)/HIV: a systematic review and metaanalysis. Syst Rev. 2019;8(1):12.

24. Lucero RJ, Frimpong JA, Fehlberg EA, Bjarnadottir RI, Weaver MT, Cook C, et al. The relationship between individual characteristics and interest in using a mobile phone app for HIV selfmanagement: Observational cohort study of people living with HIV. JMIR mHealth and uHealth. 2017;5(7):e100.

25. Morano JP, Clauson K, Zhou Z, Escobar-Viera CG, Lieb S, Chen IK, et al. Attitudes, beliefs, and willingness toward the Use of mHealth tools for medication adherence in the Florida mHealth Adherence project for people living with HIV (FL-mAPP): Pilot questionnaire study. JMIR Mhealth Uhealth. 2019;7(7):e12900.

26. Sharpe JD, Zhou Z, Escobar-Viera CG, Morano JP, Lucero RJ, Ibanez GE, et al. Interest in using mobile technology to help selfmanage alcohol use among persons living with the human immunodeficiency virus: A Florida Cohort cross-sectional study. Subst Abus. 2018;39(1):77-82.

27. Villegas N, Cianelli R, de Tantillo L, Warheit M, Montano NP, Ferrer L, et al. Assessment of technology use and technology preferences for HIV prevention among Hispanic women. Hisp Health Care Int. 2018;16(4):197-203.

28. Saberi P, Dawson Rose C, Wootton AR, Ming K, Legnitto D, Jeske $\mathrm{M}$, et al. Use of technology for delivery of mental health and substance use services to youth living with HIV: A mixedmethods perspective. AIDS Care. 2020;32(8):931-9.

29. Schnall R, Musgrove K, Batey DS. Symptom profile and technology use of persons living with HIV who access services at a community-based organization in the deep South. J Assoc Nurses AIDS Care. 2020;31(1):42-50.

30. Marhefka SL, Lockhart E, Turner D, Wang W, Dolcini MM, Baldwin JA, Roig-Romero RM, Lescano CM, Glueckauf RL. Social determinants of potential eHealth engagement among people living with HIV receiving Ryan White case management: Health equity implications from Project TECH. AIDS Behav. 2019. https://doi.org/10.1007/s10461-019-02723-1.

31. Chen AC, Lightfoot M, Szalacha LA, Lindenberg CS. A pilot, web-based HIV/STI prevention intervention targeting at-risk mexican american adolescents: Feasibility, acceptability, and lessons learned. GSTF J Nurs Health Care. 2017;4(2):86-92.
32. Wilson TE, Gousse Y, Joseph MA, Browne RC, Camilien B, McFarlane D, et al. HIV Prevention for black heterosexual men: The barbershop talk with brothers cluster randomized trial. Am J Public Health. 2019;109(8):1131-7.

33. Mansergh G, Baack BN, Holman J, Mimiaga MJ, Landers S, Herbst JH. Brief report: quantitative assessment of brief messages about HIV pre-exposure prophylaxis among HIV-infected and HIV-uninfected Black/African American and Hispanic/Latino MSM. J Acquir Immune Defic Syndr. 2019;80(1):31-5.

34. Mimiaga MJ, Closson EF, Battle S, Herbst JH, Denson D, Pitts $\mathrm{N}$, et al. Reactions and receptivity to framing HIV prevention message concepts about pre-exposure prophylaxis for Black and Latino men who have sex with men in three urban US cities. AIDS Patient Care STDS. 2016;30(10):484-9.

35. Bauer GR. Incorporating intersectionality theory into population health research methodology: Challenges and the potential to advance health equity. Soc Sci Med. 2014;110:10-7.

36. Grace D. Intersectionality-informed mixed method research: A primer. 2014 April 2014.

37. Scott N, Siltanen J. Gender and intersectionality - a quantitative toolkit for analyzing complex inequalities. 2012 December 17, 2012

38. Hankivsky O, Grace D, Hunting G, Giesbrecht M, Fridkin A, Rudrum S, et al. An intersectionality-based policy analysis framework: critical reflections on a methodology for advancing equity. Int J Equity Health. 2014;13:119.

39. Ortiz K, Cuevas AG, Salloum R, Lopez N, LaVeist-Ramos T. Intra-Ethnic Racial Differences in Waterpipe Tobacco Smoking among Latinos? Subst Use Misuse. 2019;54(1):1-10.

40. Evans CR, Erickson N. Intersectionality and depression in adolescence and early adulthood: A MAIHDA analysis of the national longitudinal study of adolescent to adult health, 1995-2008. Soc Sci Med. 2019;220:1-11.

41. Evans CR, Williams DR, Onnela JP, Subramanian SV. A multilevel approach to modeling health inequalities at the intersection of multiple social identities. Soc Sci Med. 2018;203:64-73.

42. Lizotte DJ, Mahendran M, Churchill SM, Bauer GR. Math versus meaning in MAIHDA: A commentary on multilevel statistical models for quantitative intersectionality. Soc Sci Med. 2020;245:112500.

43. Centers for Disease Control and Prevention. Estimated HIV incidence and prevalence in the United States, 2014-2018. 2020 May 2020

44. Braveman P. Health disparities and health equity: Concepts and measurement. Annu Rev Public Health. 2006;27(1):167-94.

45. Florida Department of Health. State HIV slide sets 2018 [Available from: http://www.floridahealth.gov/diseases-and-conditions/ aids/surveillance/epi-slide-sets.html.

46. Centers for Disease Control and Prevention. HIV surveillance report, 2017. 2017 November 2018

47. U.S. Department of Health and Human Services. Ending the Epidemic: A plan for America 2019 [Available from: https://files.hiv. gov/s3fs-public/Ending-the-HIV-Epidemic-Counties-and-Terri tories.pdf.

48. Health Resources \& Services Administration. Ryan White HIV/ AIDS Program Clients Served, by State 2017 [Available from: https://hab.hrsa.gov/stateprofiles2017/\#/profile.

49. AIDSVu. Local data: Florida rates of persons living with HIV 2016 [Available from: https://aidsvu.org/local-data/united-states/ south/florida/.

50. Lockhart E, Turner D, Marhefka SM. Considerations for partnering with RWCMs to create equitable opportunity for PLWH to participate in research. 2020. Manuscript Submitted for Publication.

51. Raymond HF, Al-Tayyib A, Neaigus A, Reilly KH, Braunstein S, Brady KA, et al. HIV among MSM and heterosexual women in 
the United States: An ecologic analysis. J Acquir Immune Defic Syndr. 2017;75(Suppl 3):S276-80.

52. Centers for Disease Control and Prevention. Diagnoses of HIV infection in the United States and Dependent Areas, 2018: Technical notes 2018 [updated May 8, 2020. Available from: https:// www.cdc.gov/hiv/library/reports/hiv-surveillance/vol-31/content/ technical-notes.html\#references.

53. te Grotenhuis M, Pelzer B, Eisinga R, Nieuwenhuis R, Schmidt-Catran A, Konig R. A novel method for modelling interaction between categorical variables. Int J Public Health. 2017;62(3):427-31.

54. Pew Research Center. Mobile Fact Sheet 2019 [Available from: https://www.pewresearch.org/internet/fact-sheet/mobile/.

55. Seplovich G, Horvath KJ, Haughton LJ, Blackstock OJ. Get+Connected: Development and Pilot Testing of an intervention to improve computer and internet attitudes and internet use among women living With HIV. JMIR Res Protoc. 2017;6(3):e50.

56. Green SM, Lockhart E, Marhefka SL. Advantages and disadvantages for receiving Internet-based HIV/AIDS interventions at home or at community-based organizations. AIDS Care. 2015;27(10):1304-1308. https://doi.org/10.1080/09540121.2015. 1051503

57. Horvath KJ, Bauermeister JA. eHealth literacy and intervention tailoring impacts the acceptability of a HIV/STI testing intervention and sexual decision making among young gay and bisexual men. AIDS Educ Prev. 2017;29(1):14-23.

58. Gakumo CA, Enah CC, Vance DE, Sahinoglu E, Raper JL. "Keep it simple": older African Americans' preferences for a health literacy intervention in HIV management. Patient Prefer Adherence. 2015;9:217-23.

59. Dworkin MS, Panchal P, Wiebel W, Garofalo R, Haberer JE, Jimenez A. A triaged real-time alert intervention to improve antiretroviral therapy adherence among young African American men who have sex with men living with HIV: focus group findings. BMC Public Health. 2019;19(1):394.

60. Christopoulos KA, Riley ED, Carrico AW, Tulsky J, Moskowitz JT, Dilworth S, et al. A randomized controlled trial of a text messaging intervention to promote virologic suppression and retention in care in an urban safety-net human immunodeficiency virus clinic: The Connect4care Trial. Clin Infect Dis. 2018;67(5):751-9.

61. Crenshaw K. Demarginalizing the intersection of race and sex: A Black feminist critique of antidiscrimination doctrine, feminist theory and antiracist politics. Univ Chic Leg Forum. 1989;140:139-67.

62. Crenshaw K. Mapping the margins: Intersectionality, identity politics, and violence against women of color. Stanford Law Rev. 1991;43(6):1241-99.

63. McCall L. The complexity of intersectionality. Signs (Chic). 2005;30(3):1771-800

64. Rouhani S. Intersectionality-informed quantitative research: A primer. 2014 April 2014.

65. Algarin AB, Zhou Z, Cook CL, Cook RL, Ibanez GE. Age, sex, race, ethnicity, sexual orientation: Intersectionality of marginalized-group identities and enacted HIV-related stigma among people living with HIV in Florida. AIDS Behav. 2019;23(11):2992-3001.

66. Logie CH, Marcus N, Wang Y, Kaida A, O'Campo P, Ahmed $\mathrm{U}$, et al. A longitudinal study of associations between HIVrelated stigma, recent violence and depression among women living with HIV in a Canadian cohort study. J Int AIDS Soc. 2019;22(7):e25341.

67. Ingram L, Stafford C, Deming ME, Anderson JD, Robillard A, Li X. A systematic mixed studies review of the intersections of social-ecological factors and HIV stigma in people living with HIV in the US South. J Assoc Nurses AIDS Care. 2019;30(3):330-43.

68. Jackson-Best F, Edwards N. Stigma and intersectionality: A systematic review of systematic reviews across HIV/AIDS, mental illness, and physical disability. BMC Public Health. 2018;18(1):919.

69. Agenor M, Perez AE, Koma JW, Abrams JA, McGregor AJ, Ojikutu BO. Sexual orientation identity, race/ethnicity, and lifetime HIV testing in a national probability sample of US women and men: An intersectional approach. LGBT Health. 2019;6(6):306-18.

70. Sangaramoorthy T, Jamison A, Dyer T. Intersectional stigma among midlife and older Black women living with HIV. Cult Health Sex. 2017;19(12):1329-43.

71. Witzel TC, Nutland W, Bourne A. What are the motivations and barriers to pre-exposure prophylaxis (PrEP) use among Black men who have sex with men aged 18-45 in London? Results from a qualitative study. Sex Transm Infect. 2019;95(4):262-6.

72. Beach LB, Greene GJ, Lindeman P, Johnson AK, Adames CN, Thomann M, et al. Barriers and facilitators to seeking HIV services in Chicago among young men who have sex with men: Perspectives of HIV service providers. AIDS Patient Care STDS. 2018;32(11):468-76.

73. Bauer GR, Scheim AI. Advancing quantitative intersectionality research methods: Intracategorical and intercategorical approaches to shared and differential constructs. Soc Sci Med. 2019;226:260-2.

74. MacCarthy S, Barreras JL, Mendoza-Graf A, Galvan F, Linnemayr S. Strategies for improving mobile technology-based HIV prevention interventions with latino men who have sex with men and latina transgender women. AIDS Educ Prev. 2019;31(5):407-20.

75. Health Resources \& Services Administration. About the Ryan White HIV/AIDS Program 2020 [updated February 2019. Available from: https://hab.hrsa.gov/about-ryan-white-hivaids-progr am/about-ryan-white-hivaids-program.

Publisher's Note Springer Nature remains neutral with regard to jurisdictional claims in published maps and institutional affiliations. 